\title{
Governance Challenges Constraining Business Process Management: The Case of a Large South African Financial Services Corporate
}

\author{
Carmen Doyle and Lisa F. Seymour ${ }^{(凶)}(\mathbb{D}$ \\ University of Cape Town, Cape Town, WC, South Africa \\ lisa.seymour@uct.ac.za
}

\begin{abstract}
Obtaining and maintaining a competitive advantage is vital for profit-driven organizations. Business Process Management (BPM) and the governance thereof offer such organizations a framework of management practices within which to achieve this goal. The objectives of this study were to identify and describe the BPM governance challenges that constrain BPM in large South African corporates as BPM in South Africa had not previously received any comprehensive BPM governance focus. Additionally, the BPM and BPM governance bodies of knowledge lack literature on studies focused on BPM governance challenges. Qualitative research methods were utilized to collect useful and descriptive data through secondary document collection and interviews in a single case study. The study confirmed eight of the literatureidentified governance challenge themes that constrain BPM and contributed eleven new BPM governance challenge themes to the BPM and BPM governance body of research.
\end{abstract}

Keywords: Business process management governance $\cdot$ Business Process Management $\cdot$ Financial services

\section{Introduction}

Business Process Management (BPM) is a considered, all-encompassing solidification of process practices sharing a common belief that an approach centered on processes leads to significant advancements in system compliance and performance $[1,2]$. Increased resource availability, awareness, attention, and formalized responsibility facilitate an increase in BPM success [3]. Though BPM has yielded some success, and despite significant organizational investments in BPM activity, BPM still experiences implementation and expansion challenges [4]. These challenges relate to organizations' inadequate grasp of their methodologies. Additionally, organizations often apply adhoc, instead of organization-wide (org-wide), enhancements that yield more effective and longer-term results $[4,5]$. It, therefore, is apparent that an understanding of the various aspects that facilitates BPM success remains vital [5, 6]. To this end, BPM provides a governance structure that regulates the modernization of alwaystransforming businesses and org-wide value chains [2]. 
BPM governance's impact is far-reaching. It allows organizations to monitor and scrutinize their BPM practices, BP performance, and outcomes. BPM governance, furthermore, helps to rank the importance of BP improvements, increase the organization's capabilities, and manage downstream improvement initiatives [5, 7, 8]. Still, enterprises often struggle to address BPM challenges effectively $[9,10]$. The literature is unable to assist as it lacks empirical examination of the business aspects that cause governance-related challenges in BPM. Hence the grand challenge from the BPM 2019 conference that we "take a more empirical angle in our work, trying to identify genuine issues that organizations are facing" [11]. To contribute to this knowledge gap, this study's research question was "What are the governance challenges that constrain BPM in a large South African financial services corporate?" Thus, this paper aimed to describe the corporate's governance-related BPM experiences. The sections that follow provide an overview of the relevant literature, detail of the research method and case description, the results of the findings, followed by research limitations and suggested future research.

\section{Literature Review}

This section summarises the literature on BPM, BPM governance, and governancerelated BPM challenges. The study's theoretical framework is then discussed, followed by the literature summary.

BPM interest remains on the rise [7]. Since companies employing BPM practices elevated their levels of interest in the realization of BPM benefits, BPM methodology skills have become sought-after. Benefits realization is achievable when these organizations follow a BPM framework. Frameworks should be well-thought-out to enable BPM understanding as enterprise expertise instead of insulated process improvement initiatives [12]. BPM's comprehensive nature and environment also require a framework construction such that it supports its complexity breakdown [13].

Much research on governance, its meaning, relevance, and benefits are evident in the literature. It is, therefore, no longer perceived as a new concept [14]. BPM governance focuses on process assets as quantifiable assets [14]. This research study adopts the comprehensive view that BPM governance comprises a management framework aimed at guiding all BP-related decision-making and design. Thus, it focusses on the functional, cross-functional, and cross-business unit, org-wide initiatives, and all of its BPM-related practices [1,9]. Cited BPM governance elements include BP standards, $\mathrm{BP}$ roles and responsibility, BP objectives, control methods, assessment methods, governance structures, architecture, and infrastructure [15].

\subsection{Theoretical Framework}

This study examines governance challenges that constrain BPM, to assist Table 1 represents BPM governance challenges derived from the literature which was derived as follows. Firstly elements and their challenges were identified from the literature and then re-categorise into a known BPM governance framework selected to guide the data collection. Secondly, the researcher rationalized the BPM governance categories, 
themes, and sub-themes identified in the BPM governance frameworks found in the literature. These frameworks are (1) the de Bruin and Rosemann BPM Maturity Model [13]; (2) the Bhat and Fernandez elements of BPM Governance [16], and (3) the Spanyi BPM governance framework checklist [8]. Next, the researcher mapped the six literature-derived BPM governance categories, along with their themes and elements, to the five capability areas contained in the de Bruin and Rosemann BPM Maturity Model's governance factor [13]. The five BPM governance capability areas are (1) Process Management (PM) Decision-making; (2) PM Roles and Responsibilities; (3) PM Metrics and Performance Linkage; (4) PM Standards; and (5) PM Controls. Lastly, the researcher removed the BPM governance elements as they were useful to the framework construction only for categorising the corresponding challenges.

Table 1. A summary of the literature-derived BPM governance challenges

\begin{tabular}{|c|c|c|}
\hline Category & Related challenges & Authors \\
\hline \multirow[t]{2}{*}{ PM standards } & $\begin{array}{l}\text { Lack of standard methods } \\
\text { Lack of effective BP's } \\
\text { Lack of robust BPMG frameworks } \\
\text { Lack of BP enhancement methods }\end{array}$ & $\begin{array}{l}{[8,15-} \\
18]\end{array}$ \\
\hline & $\begin{array}{l}\text { Lack of training, skills definition } \\
\text { Lack of adequate incentive schemes } \\
\text { Lack of suitable academic programs } \\
\text { Lack of BPM definition and shared vision }\end{array}$ & $\begin{array}{l}{[8,15,} \\
17]\end{array}$ \\
\hline \multirow[t]{4}{*}{$\begin{array}{l}\text { PM metrics and performance } \\
\text { linkage }\end{array}$} & $\begin{array}{l}\text { Lack of management focus: } \\
\text { How to strategically align BPs to objectives } \\
\text { Essential information systems' strategic } \\
\text { alignment }\end{array}$ & {$[19]$} \\
\hline & $\begin{array}{l}\text { Lack of attainable \& complex maturity } \\
\text { models } \\
\text { Lack of representation of customer and org- } \\
\text { wide } \\
\text { Cooperation needs in popular reference } \\
\text { models }\end{array}$ & {$[8,18]$} \\
\hline & Low enterprise integration & {$[15,17]$} \\
\hline & $\begin{array}{l}\text { Lack of BP infrastructure integration } \\
\text { Lack of internal client infrastructure } \\
\text { Difficulties relating to legacy systems }\end{array}$ & {$[15-18]$} \\
\hline PM controls & Difficulty with legislation & [15-18] \\
\hline PM roles and responsibilities & $\begin{array}{l}\text { Lack of role definition, BPM skilled roles } \\
\text { Loyalty division (admin and process) } \\
\text { Resistance to change } \\
\text { Traditional BPM governance leadership } \\
\text { Slow changing executive thinking }\end{array}$ & $\begin{array}{l}{[8,17,} \\
20]\end{array}$ \\
\hline
\end{tabular}

Despite BPM governance's significant role within organizations and, particularly in BPM initiatives, it is still an unsuitably addressed enterprise issue. Management 
commitment remains essential to attain favorable BPM maturity and to transform strategy into realized benefits. Still, as organizations are not able to effortlessly commit, these challenges persist and effective org-wide deployment of these elements' progress remains slow and minimal. The literature review did not surface any studies that have comprehensively examined BPM governance challenges. Thus, the need for the comprehensive examination of BPM governance challenges in all business sectors, industries, and context is substantiated.

\section{Method and Case Description}

The study's research question, research objectives, research strategy and literature guided the data collection. The research objective was to identify and describe governance challenges constraining BPM in large South African financial services corporates. The study embraced a subjective ontological stance and an interpretivist epistemological stance, which promoted understanding the research participants, their interactions, and their impact on the world around them [21]. The purpose of the study was descriptive, and qualitative research methods were employed. By using a case study research strategy, the study described the BPM governance challenges experienced and perceived by the case organization, as well as the complexities that influence these experiences $[22,23]$. The single case study organization was known as InvestCo throughout the study to ensure anonymity. At the time, the primary author had been in the case organization's service for many years. Thus, the author had a fair understanding of its strategic objectives and culture. InvestCo was selected for this research study because (1) it is considered one of the largest private sector investment managers in South Africa with an employee count of over 500 and several branches over the breadth of the country; (2) it has not officially adopted BPM; (3) though its maturity level was low, it had established process management practices.

Table 2. Research participants' business roles

\begin{tabular}{l|l}
\hline Position & Experience \\
\hline Senior IT manager (3) & $19,10,15$ years \\
\hline Senior business analyst (2) & 14,5 years \\
\hline Senior operations manager (1) & 21 years \\
\hline Senior analyst programmer (1) & 6 years \\
\hline Senior compliance officer (1) & 11 years \\
\hline
\end{tabular}

The eight participants in Table 2, were purposely sampled. InvestCo's Management-level employees were deemed more likely to contribute to a broader view of the role of BPM governance and its enterprise-wide impact on their organization. InvestCo's organizational permission was secured after the study received university ethical clearance. Useful and descriptive data was obtained through semi-structured interviews with the relevant subject matter experts within the organization. Secondary data (Table 3) was obtained through document collection to achieve triangulation [24]. 
Table 3. Research study-related secondary data

\begin{tabular}{l|l|l|l}
\hline SDID & Description & SDID & Description \\
\hline SDST01-4 & PM standards & STDOTH01-03 & Case description \\
\hline SDST04 & PM metrics and performance linkage & STDOTH02 & Case description \\
\hline SDCT01-6 & PM controls & STDOTH03 & Case description \\
\hline
\end{tabular}

The interview protocol ensured that participants were informed of the study's purpose and allowed the flexibility to adjust the interview to suit the outcomes of the individual interviews [25]. After transcribing all interviews, thematic analysis of the data was performed iteratively using Nvivo, and themes were inductively coded as they emerged from the data following Braun and Clarke's method [27]. The analysis took place concurrently with the data collection [24]. The secondary data was analysed in the same wasy as the primary data. The first phase included reading and rereading the data and noting initial ideas. The second phase resulted in initial coding. In the third phase the codes where collated into themes and in the fourth phase the themes were iteratively reviewing by re-reading all text. The final two phases included naming and renaming themes and selecting vivid extracts for each theme. The literature-derived theoretical framework merely served to guide the study and categorization of themes that emerged from the data. The principle of contextualization acknowledges that contextual differences bring about variances in experiences, perceptions, and understanding [26].

\section{Research Findings}

This study aimed to describe the BPM governance challenges experienced in the financial services industry. Through the thematic analysis of the research data, the study derived 19 BPM governance-related themes and 31 BPM governance-related sub-themes. A discussion of the themes appearing now follows. The theoretical framework employed in this study served as a lens for the categorization of the themes to render the research findings comparable to the literature.

\subsection{Lack of PM Controls}

The thematic analysis of the data highlighted six PM controls-related challenges. Table 4 reflects data excerpts related to the challenges discussed. 
Table 4. PM-controls-related BPM governance challenges

\begin{tabular}{|c|c|}
\hline Theme & Text reference \\
\hline $\begin{array}{l}\text { Difficulty with capacity } \\
\text { constraints }(\mathrm{C} 1)\end{array}$ & $\begin{array}{l}\text { "Technical debt is our biggest problem. We know what we } \\
\text { need to fix, but we run lean teams - Lean, as in our teams } \\
\text { are too few for how much work needs to be done." [RP06] }\end{array}$ \\
\hline $\begin{array}{l}\text { Lack of pre-change control } \\
\text { rigor }(\mathrm{C} 2)\end{array}$ & $\begin{array}{l}\text { "Change Control Forum is to identify ahead of time } \\
\text { downstream side effects rather than just before } \\
\text { implementation." [RP08] }\end{array}$ \\
\hline $\begin{array}{l}\text { Impact of external parties on } \\
\text { BPs (C3) }\end{array}$ & $\begin{array}{l}\text { "Regulatory changes take precedence over anything that } \\
\text { has an impact on daily trading or client reporting, and } \\
\text { after that, the internal processes that aim to improve the } \\
\text { existing world." [RP08] }\end{array}$ \\
\hline Lack of BPM architecture (C4) & $\begin{array}{l}\text { "Everything is available, and you can find it, it is just that } \\
\text { we do not have one, big, process library" [RP06] }\end{array}$ \\
\hline $\begin{array}{l}\text { Risk around remaining manual } \\
\text { BPs (C5) }\end{array}$ & $\begin{array}{l}\text { "We still have manual BPs, and it brings the risk for } \\
\text { errors." [RP07] }\end{array}$ \\
\hline $\begin{array}{l}\text { Lack of established BP } \\
\text { controls and criteria (C6) }\end{array}$ & $\begin{array}{l}\text { A boutique will have BPs mapped, and their business } \\
\text { process is its IP (intellectual property), which is why it } \\
\text { stays inside the boutique." [RP06] }\end{array}$ \\
\hline
\end{tabular}

Difficulty with Capacity Constraints. The organization's capacity-related challenges pertained to resourcing difficulty, workforce retention, and the complexities around skilled recruitment. Technical debt was said to include the nice-to-have BP improvement initiatives that, due to strategic priorities, higher priority focuses, and capacity constraints, never reach the top of the list.

Lack of Pre-change Control Rigor. Lack of pre-change control rigor challenges comprises a lack of solution design rigor, data governance, and problematic sub-team cultures. Thus, the understanding of BP change requests and implementations need to be adjusted. Adequate data governance is required as data-related updates have a potentially more significant impact on the organization.

Impact of External Parties on BPs. The participants mentioned that external parties that often impact the organization's various BPs included their outsourced administrator, data vendors (includes the economic markets), and regulatory bodies. When incidents, originating with the outsourced service provider or data vendors, occur, all business-as-usual activity ceases until the issues are resolved.

Lack of BPM Architecture. Although all BP artifacts are available and accessible, awareness is lacking, and storage of these artifacts are not centralized. The lack of dedicated storage resources and policies cause much frustration, particularly when artifacts are stored in multiple locations with various version numbers.

Risk Around Remaining Manual BPs. Concerns exist around the organization's few remaining manual BPs. The secondary data suggests the challenge lies somewhere 
between business-and-IT oversight and prioritization. These issues are possibly brought about by the capacity constraint difficulties mentioned earlier.

Lack of Established BP Controls and Criteria. There is the perception that the organization does not have a high-level process management plan. This perception exists as the organizational structure necessitates role-based access and permissions.

\subsection{Lack of PM Roles and Responsibilities}

The thematic analysis highlighted nine PM roles and responsibilities-related challenges. Table 5 reflects data excerpts related to the challenges which are now discussed.

Difficulty Resulting from the Business Unit (BU) Structuring. Participants shared that the way in which the organization structures its business units and its lean strategic stance of managing income and costs were at the root of the challenges that they are experiencing. The secondary data supported the participants' experiences.

Lack of Governance Structures. There was no mention of an officially defined obligation to adhere to BPM or BPM governance. All participants mentioned that their BPM and BPM governance roles were informal. Furthermore, there was a strong sense that cost-saving, and not BPM, had been the strategic goal for the last few years.

Lack of BPM Roles and Governance Discipline. No-one is formally driving BPM in the organization. Concerns exist about the organization's perception that documentation of BPs ownership resides in IT. Additionally, concerns exist about the current inability to track BP ownership activity once the BP is handed over to the business.

Ineffective BP Design Process. Challenges experienced when the upfront BP design process does not include Information Systems and IT representatives. Often, the business will only discover this oversight when the solution encounters its first exception in a production environment.

Lack of BPM Principles and Practices. The challenges that participants mentioned included the fact that no-one was monitoring business activity, or whether they employed BP standards and best practices. Furthermore, no enforcement of best practices was evident in this regard.

Resistance to Change. Some of the business units' resistance to change relates to the fear of redundancy. Therefore, they have not been able to embrace the opportunities that automation delivers.

Division of Loyalty. Process owners lack authority. Thus complexities, such as capacity constraints, appear to exacerbate the problem. This complexity is particularly true when process managers attempt to manage their BPM initiatives.

Lack of Catalog Management. Process catalogs are lacking and would serve as upfront communication around the business' service offerings and process involved with securing those services. In the absence of such a catalog, it is particularly challenging to coordinate building-block BPs. 
Ineffective BP Prioritization. Various managers review and prioritize work packages. Thus, when the last manager reviews a business units' work package list and, their opinion of priority may differ from another manager's opinion. Such an initiative may then unnoticeably drop of the worklist, or execute without an actual business need.

Table 5. PM roles and responsibility-related BPM governance challenges

\begin{tabular}{|c|c|}
\hline Theme & Text reference \\
\hline $\begin{array}{l}\text { Difficulty resulting from the } \mathrm{BU} \\
\text { structuring }(\mathrm{C} 7)\end{array}$ & $\begin{array}{l}\text { The main thing they care about is alpha, and not the data } \\
\text { integrity, even though data integrity is central to alpha. } \\
\text { [RP08] }\end{array}$ \\
\hline $\begin{array}{l}\text { Lack of governance structures } \\
\text { (C8) }\end{array}$ & $\begin{array}{l}\text { "We do not typically think of BPM as a practice in the } \\
\text { everyday world." [RP04] }\end{array}$ \\
\hline $\begin{array}{l}\text { Lack of BPM roles and } \\
\text { governance discipline }(\mathrm{C} 9)\end{array}$ & $\begin{array}{l}\text { "I think what the organization lacks in terms of BPM is } \\
\text { someone to see that it gets done, that there are standards, } \\
\text { implemented, tools used, and best practices implemented." } \\
{[\mathrm{RP} 02]}\end{array}$ \\
\hline $\begin{array}{l}\text { Ineffective BP design process } \\
\text { (C10) }\end{array}$ & $\begin{array}{l}\text { "IT is bolted onto the decided upon the business process. } \\
\text { Any controls we build are never going to be complete } \\
\text { controls." [RP08] }\end{array}$ \\
\hline $\begin{array}{l}\text { Lack of BPM principles and } \\
\text { practices }(\mathrm{C} 11)\end{array}$ & $\begin{array}{l}\text { "What is passed on is "Do this," not "Why we are doing } \\
\text { this." This lack of context leads to people doing what they } \\
\text { are told" [RP08] }\end{array}$ \\
\hline Resistance to change (C12) & $\begin{array}{l}\text { "They are only now starting to speak up because someone } \\
\text { has left, and now realize that they have an issue." [RP06] }\end{array}$ \\
\hline Division of loyalty (C13) & $\begin{array}{l}\text { "So much pressure ... to deal with people that are } \\
\text { overworked because of under-resourcing, and I am not the } \\
\text { line manager." [RP03] }\end{array}$ \\
\hline $\begin{array}{l}\text { Lack of catalog management } \\
\text { (C14) }\end{array}$ & $\begin{array}{l}\text { "Every request should have an associated BP - which also } \\
\text { speaks to this idea of a service catalog which has come } \\
\text { up." [RP06] }\end{array}$ \\
\hline $\begin{array}{l}\text { Ineffective BP prioritisation } \\
\text { (C15) }\end{array}$ & $\begin{array}{l}\text { Different subject matter experts log or create the work } \\
\text { packages; there might be underlying differences in the } \\
\text { interpretation of exactly how fair the alignment is with the } \\
\text { strategy. [RP01] }\end{array}$ \\
\hline
\end{tabular}

\subsection{Lack of PM Standards}

The thematic analysis of the data highlighted two PM standards-related challenges. Table 6 reflects data excerpts related to the challenges which are now discussed.

Lack of BP Documentation Standards. BP documentation that does not include the process' key risk areas, escalation points, or frequently asked questions is often the result of ineffective BP's. The lack of secondary data supports the participant's views that the organization does not currently enforce any particular BPM standard and very few BPM governance standards. 
Ineffective Employee Assessment. Unclear links exist between the management of BPs and the organization's incentive reward system. Though the secondary data lightly hinted at his link, the association could easily be overlooked when the staff has a small window to read non-BP related communications. Non-standard requests do not have existing BPs and often result in dissatisfied clients.

Table 6. PM standards-related BPM governance challenges

\begin{tabular}{l|l}
\hline Theme & Text reference \\
\hline $\begin{array}{l}\text { Lack of BP documentation } \\
\text { standards (C16) }\end{array}$ & $\begin{array}{l}\text { "They sometimes miss critical information that would have an } \\
\text { impact on the effectiveness of that specific business process." } \\
\text { [RP01] }\end{array}$ \\
\hline $\begin{array}{l}\text { Ineffective employee } \\
\text { assessment (C17) }\end{array}$ & $\begin{array}{l}\text { "Initiatives should be better aligned with our rewards } \\
\text { recognition process. [RP02] "There is frustration on both } \\
\text { sides. But, again, that is an outcome of poor work } \\
\text { management on the part of the influencer." [RP08] }\end{array}$ \\
\hline
\end{tabular}

\subsection{Lack of PM and Performance Linkage}

The thematic analysis of the data highlighted two PM metrics and performance linkage-related challenges. Table 7 reflects data excerpts related to the challenges which are now discussed.

Ineffective Business Unit Monitoring Capabilities. A concern exists that business units might not all have useful monitoring capabilities. All of the participants felt that the lack of regular BP review was capacity-related.

Ineffective Performance Review Criteria. The organization's consideration of the criteria that determined the effectiveness of their BPs' performance is lacking. The missing criteria relate to framework-fit and effective use of staff and teams.

Table 7. PM and performance linkage-related BPM governance challenges

\begin{tabular}{|c|c|}
\hline Theme & Text reference \\
\hline $\begin{array}{l}\text { Ineffective BU monitoring } \\
\text { capabilities (C18) }\end{array}$ & $\begin{array}{l}\text { "We have not, and I think that might be one of our failings, } \\
\text { but the business is now asking how can we get that, as } \\
\text { well?"” [RP08] }\end{array}$ \\
\hline $\begin{array}{l}\text { Ineffective performance } \\
\text { review criteria }(\mathrm{C} 19)\end{array}$ & $\begin{array}{l}\text { "Broader criteria such as is this allocated to the most } \\
\text { applicable team?' are not part of the conversation." [RP08] }\end{array}$ \\
\hline
\end{tabular}

\section{Discussion}

The discussion of the research findings was used to answer the research question, "What are the governance challenges that constrain BPM?" Table 8 contains a matrix of the 19 challenges that emerged from the research study, the codes are in Tables 4, 5, 
6 and 7. New themes not found in the literature are indicated with an asterisk. While the dominance of certain challenges can't be simplisticly assigned to the number of text references it does give an indication. The interpretation of the findings also supported that the dominant challenge categories were the lack of PM controls (C1-6) with 79 text references and a lack of PM process roles and responsibilities (C7-13) with 45 text references. The dominant challenge was the difficulty with capacity constraints $(\mathrm{C} 1)$ with 35 text references. No evidence was found to support the PM Decision-Making category within the case organisation. To mitigate potential bias in the grouping of the challenge, interviewees were consulted during the latter part the analysis process. As most of the organization's functions require specialized skills, the recruitment and retention policies require closer scrutiny to assess how they can aid in reducing the challenges experienced in this area. The lack of BP documentation standards challenge is brought about by a lack of organizational policies and results in inconsistent standards applied by individuals. The next steps for the organization are to address influencing policies, prioritize BPM, and embed the much-needed BPM and BPM governance principles, practices, and training.

Table 8. Summarised comparison of BPM governance challenge themes with Data sources (DS) and Text references (TR) to the literature.

\begin{tabular}{l|l|r|l|l|l|r|l}
\hline$\#$ & DS & TR & New*/Existing & $\#$ & DS & TR & New*/Existing \\
\hline C1 & 8 & 35 & $*$ & C11 & 3 & 6 & \\
\hline C2 & 3 & 13 & $*$ & C12 & 1 & 4 & \\
\hline C3 & 5 & 12 & & C13 & 1 & 2 & \\
\hline C4 & 5 & 10 & & C14 & 1 & 1 & \\
\hline C5 & 3 & 5 & $*$ & C15 & 1 & 1 & $*$ \\
\hline C6 & 3 & 4 & $*$ & C16 & 6 & 17 & \\
\hline C7 & 5 & 11 & $*$ & C17 & 4 & 9 & $*$ \\
\hline C8 & 4 & 9 & $*$ & C18 & 6 & 13 & $*$ \\
\hline C9 & 3 & 6 & & C19 & 2 & 3 & $*$ \\
\hline C10 & 3 & 5 & $*$ & & & & \\
\hline
\end{tabular}

\section{Conclusion}

This paper described South African Financial Services governance-related BPM experiences. This study found support for eight of the existing BPM governance challenges identified in the literature. The matching challenges were those that could be generalized across multiple organizations and industries. Additionally, the study has added contextual variation to existing themes, as well as introducing eleven new themes. This empirical study contributes to the BPM and BPM governance body of research in two ways. The study contributes to practice in that its comprehensive BPM governance theoretical framework, together with the literature-derived BPM governance elements framework could hold great value for future top management BPM and 
BPM governance-related decision-making in financial services and similar organizations. Not forgetting, though, that any framework should be adjusted to suit the context in which it is used. The study contributes to theory, in that it provides an initial contribution to BPM governance challenges-focused research.

The specific research focus may limit the generalizability of the study's findings. The following research limitations are inherent in the study. Single case studies' research findings and their application may not be generalizable. Instead, this study's findings relate to financial services organizations with informal BPM and BPM governance practices and low BPM maturity levels. Additionally, the collection of more abundant data would have compromised the case organization's competitive and strategic advantage. The main author's proximity to the case organisation introduces potential bias, the possibility exists that the analysis process may have resulted in some inaccuracies. The literature review identified that research gaps remain concerning BPM governance challenges-focused research. South Africa was the deliberate focus as the literature review indicated that a comprehensive examination of the governance challenges constraining BPM had not yet been conducted in the global context, developing context, or the South African context. Therefore, we encourage researchers and practitioners to conduct further empirical studies of the same or similar phenomena, using different research paradigms. Such studies would yield incredibly rich and comprehensive contributions to the BPM and BPM governance bodies of knowledge.

\section{References}

1. Rosemann, M., vom Brocke, J.: The six core elements of business process management. In: vom Brocke, J., Rosemann, M. (eds.) Handbook on Business Process Management 1. IHIS, 2nd edn, pp. 105-122. Springer, Heidelberg (2015). https://doi.org/10.1007/978-3-64245100-3_5

2. Grela, G.: Measurement of business processes. In: Management, Knowledge and Learning, pp. 1217-1225 (2014)

3. Hernaus, T., Vuksic, V.B., Štemberger, M.I.: How to go from strategy to results? Institutionalising BPM governance within organizations. Bus. Process Manag. J. 22(1), 173195 (2016)

4. de Bruin, T.: Business process management: theory on progression and maturity. Queensland University of Technology (2009)

5. de Boer, F.G., Müller, C.J., ten Caten, C.S.: Assessment model for organizational business process maturity with a focus on BPM governance practices. Bus. Process Manag. J. 21(4), 908-927 (2015)

6. Kohlbacher, M.: The effects of process orientation: a literature review. Bus. Process Manag. J. 16(1), 135-152 (2010)

7. Syed, R., Bandara, W., French, E., Stewart, G.: Getting it right! Critical success factors of BPM in the public sector: a systematic literature review. Australas. J. Inf. Syst. 22, 1-39 (2018)

8. Spanyi, A.: The governance of business process management. In: vom Brocke, J., Rosemann, M. (eds.) Handbook on Business Process Management 2: Strategic Alignment, Governance, People and Culture. IHIS, 2nd edn, pp. 333-349. Springer, Heidelberg (2015). https://doi.org/10.1007/978-3-642-45103-4_14 
9. Markus, M.L., Jacobson, D.D.: Business process governance. In: vom Brocke, J., Rosemann, M. (eds.) Handbook on Business Process Management 2, 1st edn, pp. 201222. Springer, Heidelberg (2010). https://doi.org/10.1007/978-3-642-01982-1_10

10. Niehaves, B., Plattfaut, R., Budde, M., Becker, J.: Business process governance: theorizing and empirical application. In: Proceedings of the Seventeenth Americas Conference on Information Systems (2011)

11. Recker, J., Reijers, H.A.: The panel discussion at BPM 2019. In: Business Process Management Workshops. BPM 2019. Lecture Notes in Business Information Processing, vol. 362, pp. vii-x (2019)

12. Trkman, P.: The critical success factors of business process management. Int. J. Inf. Manag. 30(2), 125-134 (2010)

13. de Bruin, T., Rosemann, M.: Using the Delphi technique to identify BPM capability areas. In: ACIS 2007 Proceedings, p. 42 (2007)

14. Doebeli, G., Fisher, R., Gapp, R., Sanzogni, L.: Using BPM governance to align systems and practice. Bus. Process Manag. J. 17(2), 184-202 (2011)

15. Santana, A.F.L., Alves, C.F., Santos, H.R.M., Felix, A.L.C.: BPM governance: an exploratory study in public organizations. In: Halpin, T., Nurcan, S., Krogstie, J., Soffer, P., Proper, E., Schmidt, R., Bider, I. (eds.) BPMDS/EMMSAD-2011. LNBIP, vol. 81, pp. 46-60. Springer, Heidelberg (2011). https://doi.org/10.1007/978-3-642-21759-3_4

16. Bhat, J.M., Fernandez, J.: Successful patterns of BPM governance: a case study. In: BPM 2007 Workshop on Business Process Governance, no. September 2007, pp. 16-26 (2007)

17. Valença, G., Alves, C.F., Santana, A.F.L., Oliveira, J., Santos, H.: Understanding the adoption of BPM governance in the Brazilian public sector. In: ECIS, vol. 56, no. 2013, pp. 1-12 (2013)

18. Weerakkody, V., Janssen, M., Dwivedi, Y.K.: Transformational change and business process reengineering (BPR): lessons from the British and Dutch public sector. Gov. Inf. Q. 28(3), 320-328 (2011)

19. Syed, R., Bandara, W., Hidaya, Z.: The role of committed leadership for impactful process reforms in the public sector of developing nations. In: Complete Business Process Handbook, 3rd edn. Morgan Kaufmann Publishers Inc., Burlington (2018)

20. Kettenbohrer, J., Beimborn, D., Kloppenburg, M.: Developing a governance model for successful business process standardization. In: 19th Americas Conference on Information Systems, vol. 2, no. 2, pp. 1-11 (2013)

21. Cussen, N., Cooney, T.: How can local communities use effectuation to increase local economic growth within existing levels of government support? In: 16th European Conference on Research Methods in Business and Management, pp. 392-398 (2017)

22. Myers, M.D.: Critical ethnography in information systems. In: Lee, A.S., Liebenau, J., DeGross, J.I. (eds.) Information Systems and Qualitative Research. ITIFIP, pp. 276-300. Springer, Boston, MA (1997). https://doi.org/10.1007/978-0-387-35309-8_15

23. Bhattacherjee, A.: Social Science Research: Principles, Methods, and Practices, 2nd edn. Global Text Project, Florida (2012)

24. Saunders, M., Lewis, P., Thornhill, A.: Research Methods for Business Research, 7th edn. Pearson Education Limited, Harlow (2016)

25. Birmingham, D., Wilkinson, P.: Using Research Instruments-A Guide For Researchers, no. 1. RoutledgeFalmer, London (2003)

26. Klein, H.K., Myers, M.D.: A set of principles for conducting and evaluating interpretive field studies in information systems. MIS Q. 23(1), 67-94 (1999)

27. Braun, V., Clarke, V.: Using thematic analysis in psychology. Qual. Res. Psychol. 3(2), 77101 (2006) 